\title{
Speeding Earthquake Disaster Relief
}

\section{Tn coping with recent multibillion-dollar earth- quake disasters, scientists and emergency managers have found new ways to speed and improve relief efforts. This progress is founded on the rapid availability of earthquake information from seismograph networks.}

For many years now, seismograph networks in earthquake-prone areas of the country have been providing scientists with valuable information for earthquake research. Actions taken following two recent large earthquakes show how the same information from seismograph networks can be used in very practical and immediate ways during disaster-relief efforts.

Ten seconds of strong ground shaking on the northern edge of the Los Angeles metropolitan area left more than 40,000 people homeless and as many as 16,000 residences unsafe for occupancy after the 1994

Northridge earthquake in southern California. While police and fire departments, medical emergency teams, and citizens rescued people and fought fires, emergency managers were faced with deciding what resources would be needed to shelter people and to help people recover from the disaster. These decisions would affect thousands of people whose lives were shattered or disrupted by the violent earthquake.

In responding to the disaster, emergency managers were aided by scientists and engineers from the U.S. Geological Survey (USGS) and other institutions and agencies. Scientists and engineers quickly prepared a shaking-intensity map for all parts of the greater Los Angeles area; this map showed estimated severity of shaking and the level of damage likely associated with such shaking. This map was available long before a complete picture of the damage could be assembled. It enabled emergency managers to promptly locate the hardest hit areas and to send appropriate help. Victims whose homes were destroyed or severely damaged were di-

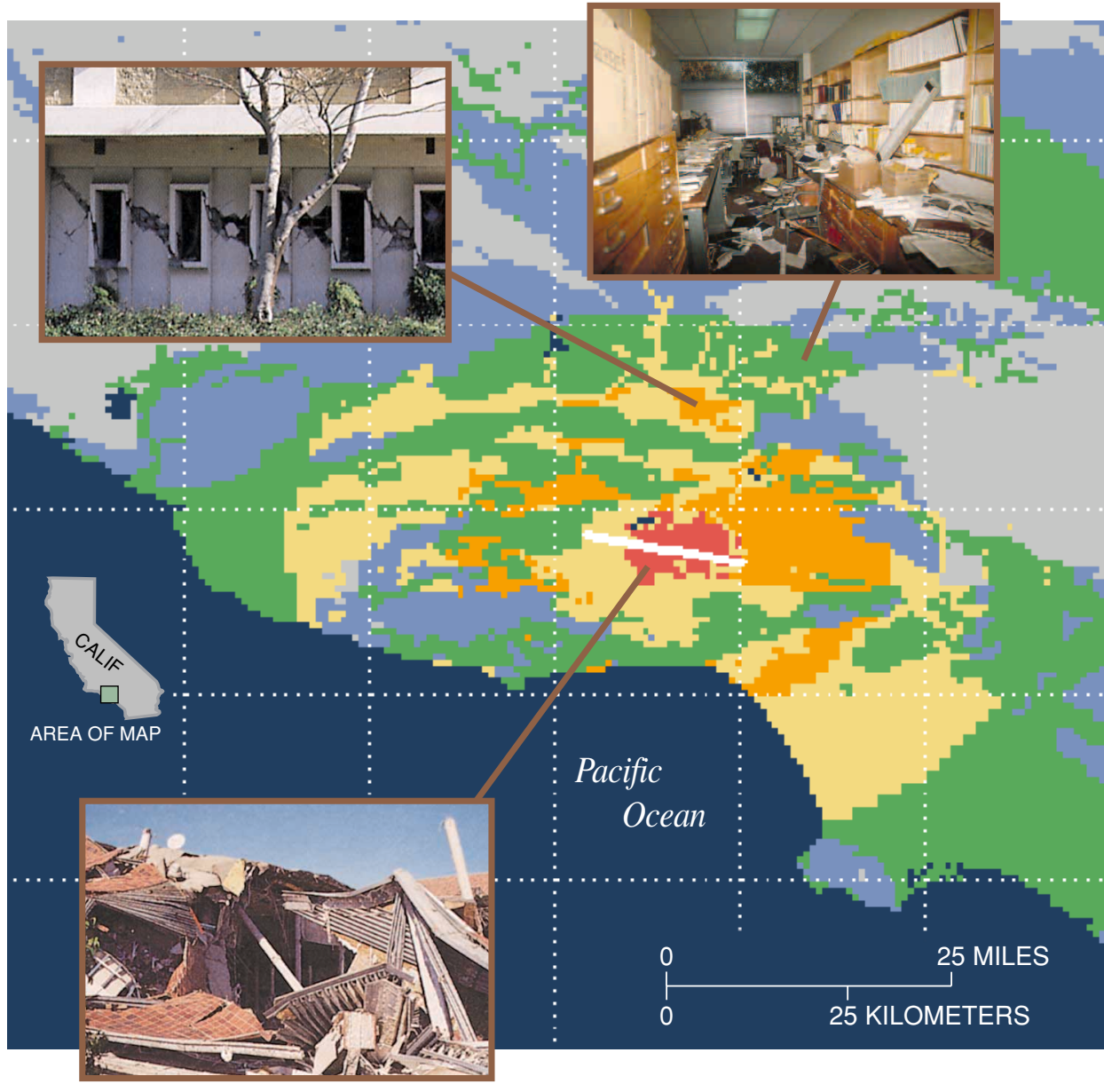

A rapidly prepared map of probable shaking intensity throughout the greater Los Angeles area that was used to bring timely emergency services to tens of thousands of victims after the devastating Northridge earthquake on January 17, 1994. Six levels of shaking intensity are shown by different colors. Red near fault (bold white line) shows area that shook most violently. Inset photographs show typical damage associated with different levels of shaking: light damage (upper right), moderate damage (upper left), and heavy damage (lower left).

rected to shelter before a predicted storm added to their misery. Teams of relief workers were sent where they were most needed in the days following the quake. The map also helped emergency managers reduce the time for delivery of relief money to individuals from weeks to hours.

The shaking-intensity map prepared after the Northridge earthquake was the first use of such a map to help focus relief efforts during a disaster. Seismologists have known for many years that damage from an earthquake is not evenly distributed about its epicenter. Although damage typically does decrease with distance from the earthquake source, local geologic conditions can greatly alter this pat- tern by amplifying shaking in specific areas; this fact is what makes shaking-intensity maps prepared after an earthquake such a valuable tool for emergency managers.

To prepare accurate shaking-intensity maps quickly after an earthquake, essential information about the location, size, and nature of the earthquake must be brought together. A comprehensive broadcast system for reporting this essential information was established in 1991 in southern California. The broadcast system, called CUBE*, automatically reports earthquakes recorded by the 350-station southern California seismograph network operated by the USGS and the California Institute of Tech*Caltech/USGS Broadcast of Earthquakes 
nology (Caltech). A companion seismograph network and broadcast system reports earthquakes in northern California; similar networks are located in other earthquake-prone areas of the nation.

Whenever a sizable earthquake strikes, designated scientists are notified via pager. Subscribers to this system — such as railroad companies, utility companies, and television stations - are also simultaneously notified. Instead of a telephone number, the location, size, depth, and other information about the earthquake scroll across the pager display. This information can be fed into a computer modeling system, which incorporates geologic conditions of an area. When a sizable earthquake occurs, scientists can use the modeling system to calculate the shaking intensity for different locales within a large area surrounding the earthquake's epicenter. They are then able to combine this information to produce a shaking-intensity map that can be used by emergency managers.

The shaking-intensity map prepared after the Northridge earthquake provided an easyto-understand picture of how shaking varied throughout the greater Los Angeles area and thus how different areas were affected. During future earthquakes expected in both southern and northern California, shaking-intensity maps can be used to focus relief resources in the hardest hit areas. When such maps are prepared within hours of a large earthquake, they have enormous potential to help disaster-relief workers quickly deliver medical help, food, and water to survivors. These maps can also be useful in directing the newly homeless to shelter.

While shaking-intensity maps are one valuable benefit of the rapid availability of infor-

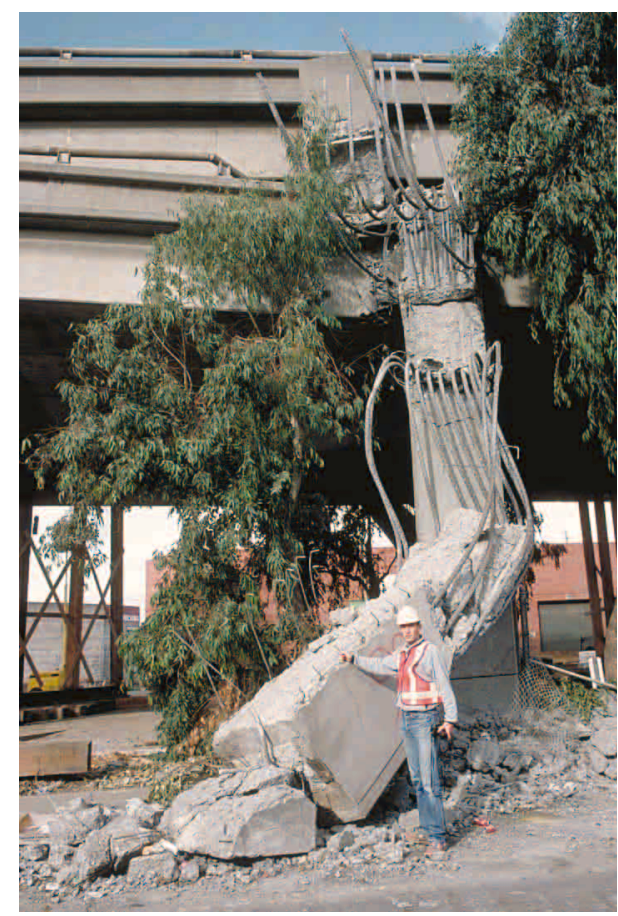

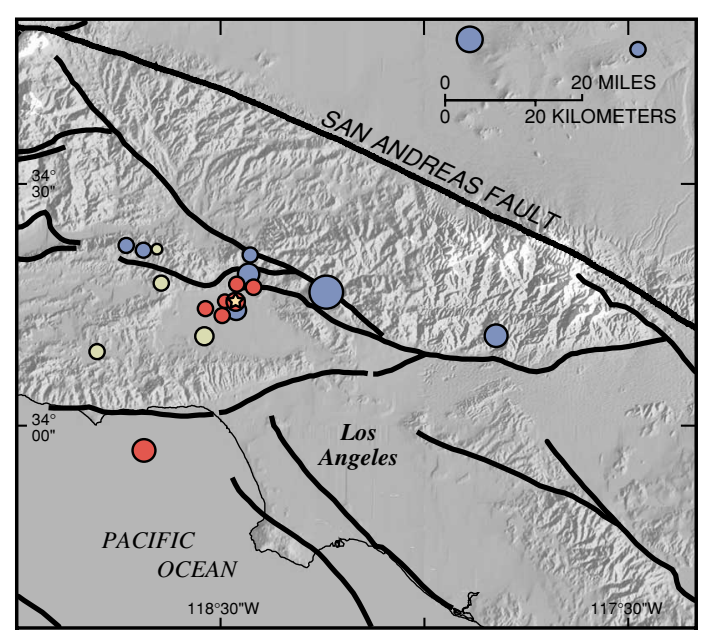
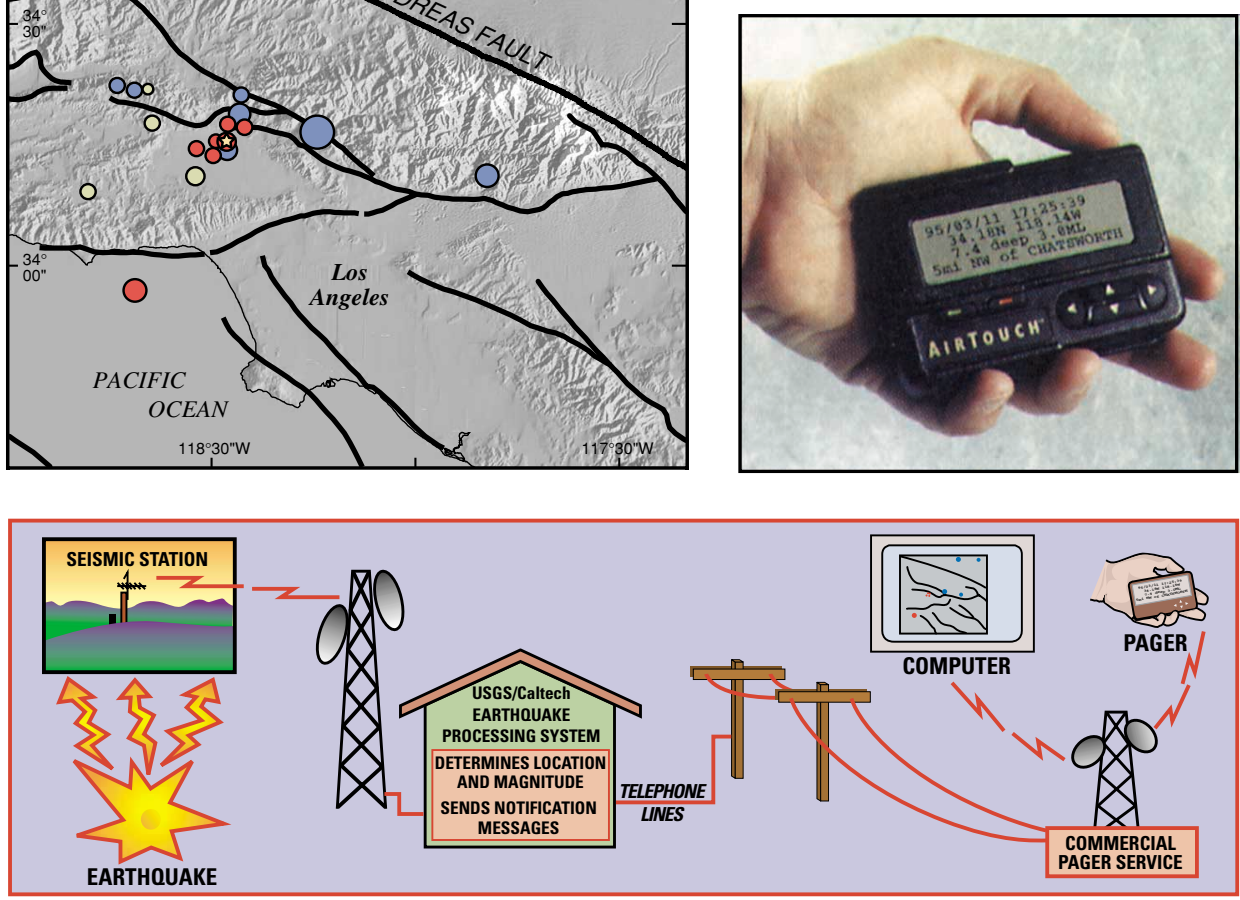

Basic elements of the broadcast system that transmits information about earthquakes in southern and northern California. Energy from earthquakes is recorded at numerous field stations on instruments called seismographs. These seismic signals are relayed nearly instantaneously from this seismograph network to analysis centers at the California Institute of Technology (Caltech) in Pasadena and at the U.S. Geological Survey in Menlo Park. From these centers, earthquake information including time, location, and magnitude is relayed to designated scientists and to system subscribers via pager (top right) within 1 or 2 minutes of an earthquake. The information can also be displayed as a map on a personal computer (top left).

mation from seismograph networks, there are other practical ways this information can be used. For example, information from the northern California seismograph network was used to warn workers of numerous aftershocks as they razed the collapsed Cypress freeway viaduct in Oakland, California, following the Loma Prieta earthquake in 1989. USGS scientists set up a system that warned workers via radio about 25 seconds before the precarious structure would begin to shake from an aftershock. These warnings, made possible because radio waves travel much faster than seismic waves, were sent from detecting instruments in the aftershock area-some 50 miles away-to a receiver at the Oakland worksite. Each time the instruments detected an aftershock, the receiver sounded an alarm that enabled workers to move to safety during the danger period.

Twisted remnant of the Cypress freeway viaduct in Oakland, California, following its partial collapse during the Loma Prieta earthquake in 1989. Because aftershocks of a large earthquake can cause additional shaking and damage, information from a seismograph network near the earthquake's epicenter was used to warn workers dismantling this structure about 25 seconds before the structure would begin shaking again.
Both these examples show how rapid, reliable information from seismograph networks, until recently used primarily for research, is now proving its value during earthquake disaster-relief operations. This information provides emergency managers with a means for coping more effectively with the earthquake disasters that are expected in the future.

$$
\begin{gathered}
\text { Carl Mortensen, Carolyn Donlin, Robert A. Page, } \\
\text { and Peter Ward } \\
\text { Graphic design by } \\
\text { Susan Mayfield and Sara Boore }
\end{gathered}
$$

\section{COOPERATING AGENCIES, COMPANIES AND INSTITUTIONS}

California Governor's Office of Emergency Services California Institute of Technology EOE International

Federal Emergency Management Agency University of California, Berkeley

\footnotetext{
For more information contact:
Earthquake Information Hotline (650) 329-4085

U.S. Geological Survey, Mail Stop 977

345 Middlefield Road, Menlo Park, CA 94025 http://quake.wr.usgs.gov
}

This Fact Sheet and any updates to it are available online at:

http://pubs.usgs.gov/fs/1995/fs097-95/ 